\title{
Adopting adequate leaching requirement for practical response models of basil to salinity
}

\author{
Hossein Babazadeh ${ }^{*}$, Mahdi Sarai Tabrizi ${ }^{1}$, and Hossein Hassanpour Darvishi ${ }^{2}$ \\ ${ }^{1}$ Science and Research Branch, ${ }^{2}$ Shahr-e-Qods Branch, \\ Islamic Azad University, Tehran, Iran
}

Received February 8, 2016; accepted June 5, 2016

\begin{abstract}
A b s t r a c t. Several mathematical models are being used for assessing plant response to salinity of the root zone. Objectives of this study included quantifying the yield salinity threshold value of basil plants to irrigation water salinity and investigating the possibilities of using irrigation water salinity instead of saturated extract salinity in the available mathematical models for estimating yield. To achieve the above objectives, an extensive greenhouse experiment was conducted with 13 irrigation water salinity levels, namely $1.175 \mathrm{dS} \mathrm{m}^{-1}$ (control treatment) and 1.8 to $10 \mathrm{dS} \mathrm{m}^{-1}$. The result indicated that, among these models, the modified discount model (one of the most famous root water uptake model which is based on statistics) produced more accurate results in simulating the basil yield reduction function using irrigation water salinities. Overall the statistical model of Steppuhn et al. on the modified discount model and the math-empirical model of van Genuchten and Hoffman provided the best results. In general, all of the statistical models produced very similar results and their results were better than math-empirical models. It was also concluded that if enough leaching was present, there was no significant difference between the soil salinity saturated extract models and the models using irrigation water salinity.

$\mathrm{K}$ e y w o r d s: irrigation water, mathematical models, salinity, threshold value
\end{abstract}

\section{INTRODUCTION}

The global outlook towards the use of medicinal plants and their natural compositions in pharmaceutical, cosmetic, and health products as well as food industries and the consequent interest of the public, authorities, and national industries emphasize the necessity of extensive fundamental and practical research on medicinal plants and herbs in this field (Ekren et al., 2012). Medicinal plants are one of the most valuable natural resources in Iran which, if

*Corresponding author e-mail: h babazadeh@hotmail.com, h_babazadeh@srbiau.ac.ir studied, planted, and developed scientifically, can play an important role in public health, employment, and non-oil exports. Considering the diversity of the climate and different ecological conditions of Iran, comprehensive research and optimum use of these plants is essential (Marotti et al., 1996). Basil (Ocimum basilicum), ie an important medicinal plant, is an annual aromatic herb belonging to the Lamiaceae family. Its stem is 15 to $45 \mathrm{~cm}$ long and the 10 to $16 \mathrm{~cm}$ long root is straight and conical (Ekren et al., 2012; Marotti et al., 1996).

Few studies have been done on basil response to salinity in areas where only saline irrigation water is available for growing this aromatic herb. At increasing soil salinity, osmotic pressure increases and the plant must consume more vital energy for specific water uptake because the plant cannot use it all only to overcome the soil solute osmotic pressure. By increasing osmotic pressure, even if there is enough water around the root, water uptake is decreased by the plant (Homaee, 1999). By decreasing the osmotic potential, free water energy decreases and the plant should consume more vital energy for getting a certain amount of water. Therefore, a part of the energy that the plant needs to grow is consumed to absorb water and consequently plant growth is reduced. Thus, understanding the plant response to different salinity levels for using brackish water resources to achieve economical crop yield is very important (Homaee, 1999; Homaee et al., 2002a).

A large number of investigations have been conducted to evaluate the responses of different plants to salinity stresses. These studies dealt with various reactions of plants to salinity, including plant response to salinity at different

(C) 2016 Institute of Agrophysics, Polish Academy of Sciences 
growth stages (Chartzoulakis and Klapaki, 2000), plant response to salinity during the growing season (Dirksen and Augustijn, 1988; Francois, 1996; Homaee et al., 2002a), plant response to simultaneous salinity and water stress (Dudley and Shani, 2003; Green et al., 2006; Homaee et al., 2002c; Skaggs et al., 2006), and plant response to simultaneous salinity and nutrients (Hosaini et al., 2009; Shenker et al., 2003).

In almost all these studies, saturated soil extract salinity was used to assess plant response to salinity. Considering basil short root, it is assumed that complete and effective leaching of the root zone is possible, and therefore it is possible to use irrigation water salinity instead of soil saturated extract salinity in root water uptake models. If this can be done, a great saving in cost and efforts for salinity measurements is achieved, which is quite useful in practical application.

The objectives of this study were to evaluate basil response to salinity quantitatively and to estimate the yield reduction threshold value and also to investigate available mathematical models for estimating basil yield based on irrigation water salinity.

Although there is a lot of evidence that basil is a salinitysensitive plant, there are no documented figures for its tolerance to salinity. Different models are presented for evaluation of plant tolerance to salinity. Many plants tolerate salinity up to a specific value called the threshold value of salinity tolerance without any detectible yield reduction. A salinity level higher than the threshold value will cause yield reduction. Several salinity models have been developed to estimate plant response to various levels of salinity. Well-known models are presented in Maas and Hoffman (1977) and Ayars et al. (2012). These models are categorized in two groups of math-empirical and statistical models.

The most well-known math-empirical models also called macroscopic models are empirical functions that describe relative crop yield based on soil water potential (Homaee, 1999). Nowadays, these models are used more frequently because of their practicality. Feddes et al. (1978) introduced a macroscopic sink term depending on soil water pressure head $h$ only as:

$$
S=\alpha(h) S_{\max },
$$

where: $S_{\max }(\%)$ represents the maximum water uptake rate and $\alpha(h)(\%)$ is a pressure head function without any dimension. Similarly, a soil salinity reduction term, $\alpha\left(h_{o}\right)$, can be used instead of $\alpha(h)$ in Eq. (2), which can be put in the form of the Maas and Hoffman (1977) equation written in terms of the average root-zone salinity as:

$$
Y_{r}=\left\{\begin{array}{lc}
1 & 0<E C<E C^{*} \\
1-b\left(E C-E C^{*}\right) & E C^{*}<E C<E C_{0}, \\
0 & E C>E C_{0}
\end{array}\right.
$$

in which $b(\%)$ is the absolute value of the slope decline versus $E C\left(\mathrm{dS} \mathrm{m}^{-1}\right), E C^{*}\left(\mathrm{dS} \mathrm{m}^{-1}\right)$ is the maximum value of salinity without a yield reduction, $E C_{0}\left(d S \mathrm{~m}^{-1}\right)$ is the lowest value of $E C$ (US Salinity Laboratory Staff, 1954; Maas and Hoffman, 1977; Steppuhn et al., 2005a). Since the linear assumption in Eq. (3) does not fully meet the real conditions in the field, van Genuchten and Hoffman (1984) proposed an alternative equation for the above-named equation in the following form:

$$
Y_{r}=\frac{1}{1+\left(\frac{E C}{E C_{50}}\right)^{p}},
$$

where: $E C_{50}\left(d S m^{-1}\right)$ is the soil salinity at which $Y_{r}(\%)$ is reduced by $50 \%$, and $p$ is an empirical, presumably crop, soil, and climate-specific dimensionless parameter. For some crops, the value of $p$ was found to be $c a .3$ when the S-shaped function was applied to salinity stress data. Equation (4) was found to describe crop salt tolerance data equally well or even better than Eq. (3) (van Genuchten and Gupta, 1993). Dirksen and Augustijn (1988) and Dirksen et al. (1993) modified Eq. (4) as follows:

$$
Y_{r}=\frac{1}{1+\left(\frac{E C^{*}-E C}{E C^{*}-E C_{50}}\right)^{p}},
$$

Eq. (5) is more realistic than Eq. (4), because of incorporating a salinity threshold value in the equation. The most important limitation for both equations arises from the difficulty involved in obtaining $E C_{50}$. Furthermore, $p$ is not yet defined physically or empirically. Indeed, $p$ is a shape parameter, as are $E C^{*}$ and $E C_{50}$, but the influence of $E C_{50}$ is larger than that of $E C^{*}$. Similarly to van Genuchten and Hoffman (1984), Homaee (1999) assumed that $p$ is crop, soil, and climate-specific, and proposed:

$$
p=\frac{E C_{50}}{E C_{50}-E C^{*}} .
$$

Since the problem of obtaining $E C_{50}$ remained unsolved, Homaee (1999) replaced $E C_{50}$ with $E C_{\text {max }}$ and proposed the following non-linear two-threshold reduction function to account for the tailing effect as well as modification for Eq. (6) (Homaee, 1999; Homaee et al., 2002a):

$$
Y_{r}=\frac{1}{1+\left(1-\alpha_{0}\right) / \alpha_{0}\left[\left(E C^{*}-E C\right) /\left(E C^{*}-E C_{\max }\right)\right]^{p}} .
$$

The reduction in $Y_{r}$ due to salinity beyond $E C^{*}$ continues significantly until a certain degree of salinity $\left(E C_{\max }\right)$ is reached. Beyond $E C_{\max }$, increasing salinity does not cause any further significant reductions in $Y_{r}$. This reflects the fact 
that at $E C \leq E C_{\max }$, the plant is still alive but the biological activities are at their minimum rate. The exponent $p$ similar to Eq. (7) can be obtained from:

$$
p=\frac{E C_{\max }}{E C_{\max }-E C^{*}} .
$$

Similarly to the theory of De Wit (1958) and van Genuchten and Hoffman (1984), the relative yield is:

$$
\frac{\int_{0}^{Z_{r}} S d z}{\int_{0}^{Z_{r}} S_{\max } d z}=\frac{T_{a}}{T_{P}}=Y_{r},
$$

in which $T_{a}$ and $T_{P}$ are actual and potential transpiration rates $\left(\mathrm{cm} /\right.$ season), respectively, and $Z_{r}(\mathrm{~cm})$ is the average root zone depth.

In recent years, other models, which in contrast to macroscopic math-empirical models have statistical basis, have also been developed. The general form of these models is $Y=f(E C e)$. The most important of these are modified Weibull (Eq. (9)), Bi-Exponential (Eq. (10)), Gompertz (Eq. (11)), and Discount (Eq. (12)), in which $Y_{r}$ and $E C_{e}$ are relative yield (\%) and average soil saturated extract salinity $\left(\mathrm{dS} \mathrm{m}^{-1}\right)$, respectively. $a$ and $C$ were constant coefficients of each equation. The unknown components of these equations are $a$ and $C$. These coefficients were determined by fitting each equation on measured data of relative yield versus $E C$.

The statistical Weibull cumulative probability distribution increases in the value from zero to one as the independent variable ranges from its upper to its lower values (Weibull, 1951). This was used as a response function to root-zone salinity, and exponentially related one variable to another. The Weibull distribution has been modified and expressed in terms of the proportionate $Y_{r}$ remaining at any $E C$ as follows:

$$
Y_{r}=\exp \left(C(E C)^{a}\right),
$$

where: the regression coefficient $C$ is always negative and defines the intensity of the relationship, and the constant $a$ reflects the shape of the response curve. Neither $C$ nor $a$ specify any distinct biophysical characteristics. The modified Weibull function has served as an analogue for the response of crop growth or yield to environmental toxicity and solute excess (Taylor et al., 1991).

A more general exponential response function given by van Genuchten and Hoffman (1984) for analysing crop salt tolerance data reads as:

$$
Y_{r}=\exp \left(C(E C)-a(E C)^{2}\right)
$$

in which the empirical constants $C$ and $a$ again lack any biophysical identity and can be evaluated by non-linear regression. van Genuchten and Hoffman (1984), Steppuhen et al. (1996), and Wang et al. (2002) used the bi-exponential function to describe the yield response of perennial ryegrass (Lolium perenne L.), wheat (Triticum aestivum L.), and elephant grass (Pennisetum purpureum Schum), respectively.

According to Lapp and Skoropad (1976), to predict human mortality during long periods, it is possible to use a form of the equation proposed by Gompertz (1825). The same equation in various forms has been applied in botany to model germination (Tipton, 1984), emergence (Gan et al., 1992), and growth (Baker et al., 1975). Steppuhen et al. (1998) compared the emergence of two Russian wild ryegrass cultivars from saline seedbeds with the Gompertz function. It can also serve as a crop yield salinity response function in the following form:

$$
Y_{r}=1-\exp [C(\exp (a(E C)))],
$$

where: empirical constant $C$ and $a$ are always negative and lack any biophysical identity, but can be evaluated by nonlinear regression.

The compound discount equation can be modified into a sigmoidal-shaped response function:

$$
Y_{r}=\frac{1}{\left[1+\left(\frac{E C}{E C_{50}}\right)^{\exp \left(s E C_{50}\right)},\right.},
$$

where: $E C_{50}$ defines $E C$ at relative crop yield equal to $50 \%$, and $s$ represents the response curve steepness. The steepness parameter equals the average absolute value of the slope $\left(d Y_{r} / d E C\right)$ of the equation through $E C_{50}$ and its steepest segments on either side of $E C_{50}$ evaluated in our study from relative yield equal from 0.3 to 0.7 . The arguments $s E C_{50}$ of the exponent in Eq. (12) contribute to a symmetrical concave-convex yield response with the inflection point at $E C_{50}$ and is analogous to the product $b E C^{*}$ of the threshold-slope model in Eq. (3). Both $s$ and $b$ (the slope of crop yield decrease line for each unit of soil water salinity increase) indicated unit decreases in root-zone salinity. As in the thresholdslope function, the modified discount function features parameters ( $s$ and $E C_{50}$ ) with identifiable biophysical characteristics (Steppuhn et al., 2005a, 2005b).

\section{MATERIALS AND METHODS}

This greenhouse experiment was conducted with 12 irrigation water salinity treatments of $1.8,2,2.2,2.5,2.8$, $3,3.5,4,5,6,8$, and $10 \mathrm{dS} \mathrm{m}^{-1}$, and a control treatment with well water $\left(1.175 \mathrm{dS} \mathrm{m}^{-1}\right)$ used for irrigation of basil in sandy loam soil in the form of the randomized complete blocks design. Each treatment was repeated in three replicates. Salinity treatments were performed by mixing Shoor River water with fresh water. The results of the chemical analysis of the Shoor River water used in this research are given in Table 1.

In this experiment, the basil was planted on May 1st, 2014. First, the plant was irrigated using drinking water with $1.2 \mathrm{dS} \mathrm{m}^{-1}$ salinity. After 2 weeks when the plants had 
T a b l e 1. Results of chemical analysis (anions and cation, milliequvalent $1^{-1}$ ) of the Shoor River water sample

\begin{tabular}{|c|c|c|c|c|c|c|c|c|c|c|c|c|c|c|}
\hline 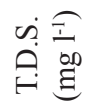 & 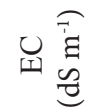 & $\mathrm{pH}$ & $\mathrm{CO}_{3}^{-}$ & $\mathrm{HCO}_{3}^{-}$ & $\mathrm{Cl}^{-}$ & $\mathrm{SO}_{4}^{-}$ & $\begin{array}{l}\text { Sum of } \\
\text { anions }\end{array}$ & $\mathrm{Ca}^{++}$ & $\mathrm{Mg}^{++}$ & $\mathrm{Na}^{+}$ & $\mathrm{K}^{+}$ & $\begin{array}{l}\text { Sum of } \\
\text { cations }\end{array}$ & SAR & $\% \mathrm{Na}$ \\
\hline 7520 & 10.49 & 7.88 & 0.04 & 4 & 70 & 49.1 & 123.1 & 10.4 & 31.6 & 76.5 & 0.17 & 118.67 & 16.69 & 64.61 \\
\hline
\end{tabular}

T a b l e 2. Climate properties in the environmental conditions

\begin{tabular}{|c|c|c|c|c|c|}
\hline \multirow{2}{*}{ Parameter } & \multicolumn{5}{|c|}{ Month } \\
\hline & May & June & July & August & Average \\
\hline \multirow{3}{*}{ Temperature $\left({ }^{\circ} \mathrm{C}\right)$} & 27.9 & 34.1 & 36.8 & 35.8 & 33.65 \\
\hline & 17 & 22.5 & 25.3 & 24.3 & 22.28 \\
\hline & 22.4 & 28.3 & 31 & 30 & 27.93 \\
\hline Relative humidity (\%) & 34 & 27 & 29 & 29 & 29.75 \\
\hline Pan evaporation rate $\left(\mathrm{mm}\right.$ day $\left.^{-1}\right)$ & 5.48 & 6.05 & 6.29 & 5.06 & 5.75 \\
\hline Light intensity $\left(\mathrm{mmol} \mathrm{m}^{-2} \mathrm{~s}^{-1}\right)$ & 725 & 1050 & 1294 & 1498 & 1142 \\
\hline
\end{tabular}

three leaves, they were irrigated using water with different salinity levels. In the environmental conditions during the study, the maximum, minimum, and average temperatures $\left(33.65,22.28,27.93^{\circ} \mathrm{C}\right)$, relative humidity $(29.75 \%)$, pan evaporation rate $\left(5.75 \mathrm{~mm} \mathrm{day}^{-1)}\right.$, and light intensity were $1142 \mathrm{mmol} \mathrm{m}^{-2} \mathrm{~s}^{-1}$ (Table 2).

One of the relatively recent methods for soil water content measurements is the theta probe instrument. The theta probe instrument (Theta Probe, Delta-T Devices, 3118-ML2, Dynamax, Inc., Houston, Tex.) consists of four probes $60 \mathrm{~mm}$ long and $3 \mathrm{~mm}$ in diameter, a waterproof container (probe structure), and a cable that links input and output signals to the data logger display. The advantages of this method are high precision and direct and rapid measurements in the field and greenhouse. The range of measurements is not limited like that of a tensiometer, and is from saturation to the wilting point. In this work, the theta probe instrument was calibrated by the weighing method for exact irrigation scheduling. Obviously, it can be calibrated by different methods (Miller and Gaskin, 1997). Our results indicated that the non-linear calibration method suggested by the producers of the theta probe instrument was the most accurate method for estimating the soil water content $\left(R M S E=0.023\right.$ and $\left.\mathrm{R}^{2}=0.935\right)$. Thus, the method of the producers of the theta probe set was used for estimating the relationship between soil water content and di-electric constant.

The theta probe set gives an average soil moisture profile between zero and $10 \mathrm{~cm}$. Soil moisture data were measured daily. Soil hydraulic parameters were calculated by the ROSETTA Code and a soil moisture characteristics curve was drawn by using five measured data at important soil potential points by a pressure plate instrument and the
RETC Code and then by using this curve, these soil moisture data were converted to soil matric potential data. Based on the water and soil balance Eq. (13):

$$
I=\left(T_{a}+D_{d}\right) \pm \Delta \mathrm{S},
$$

in which $I$ is irrigation water $(\mathrm{mm}), D_{d}$ is drain water $(\mathrm{mm})$, $T_{a}$ is actual transpiration, and $\Delta S$ is soil moisture storage changes. $I$ and $D_{d}$ were known and $\Delta S$ was measured using the theta probe set, and therefore $T_{a}$ was easily calculated.

The maximum basil root is $c a .10 \mathrm{~cm}$. By using the plant sample and extracting roots, this information was obtained during the growing period and the roots were extracted. The diameter of the pot was $24 \mathrm{~cm}$ at the top and the height was $20 \mathrm{~cm}$. Because of their shortness, the roots did not become pot bound. Relative transpiration was calculated using daily soil water content changes. A $2 \mathrm{~cm}$ thick coarse sand layer was used to decrease evaporation from the surface soil of the pots. At the end of the experiment, dry matter yield at different treatments was measured and relative yield was calculated by dividing the dry matter yield of the treatments into the dry matter yield at no stress treatment (control treatment) (Table 3).

The leaching requirement in the experimental treatments was calculated by Eq. (14) (Ayars et al., 2012):

$$
L R=\frac{E C_{i w}}{E C_{d w}},
$$

in which $L R$ is the leaching requirement, $E C_{i w}$ is electrical conductivity of the irrigation water $\left(\mathrm{dS} \mathrm{m}^{-1}\right)$, and $E C_{d w}$ is electrical conductivity of the drainage water $\left(\mathrm{dS} \mathrm{m}^{-1}\right)$ measured in each irrigation. The leaching requirement for all treatments ranged between 16.6 and $25 \%$. 
T a b l e 3. Actual dry matters at different salinity levels

\begin{tabular}{|c|c|}
\hline Salinity levels & $\begin{array}{c}\text { Dry matters } \\
\left(\mathrm{g} \text { pot area }{ }^{-1}\right)\end{array}$ \\
\hline $\mathrm{S}_{1}$ (control treatment) & 120.7 \\
\hline $\mathrm{S}_{2}$ & 108.2 \\
\hline $\mathrm{S}_{3}$ & 104.4 \\
\hline $\mathrm{S}_{4}$ & 101.6 \\
\hline $\mathrm{S}_{5}$ & 97.6 \\
\hline $\mathrm{S}_{6}$ & 94.5 \\
\hline $\mathrm{S}_{7}$ & 92.2 \\
\hline $\mathrm{S}_{8}$ & 88.0 \\
\hline $\mathrm{S}_{9}$ & 85.0 \\
\hline $\mathrm{S}_{10}$ & 80.9 \\
\hline $\mathrm{S}_{11}$ & 77.0 \\
\hline $\mathrm{S}_{12}$ & 61.3 \\
\hline $\mathrm{S}_{13}$ & 17.9 \\
\hline
\end{tabular}

Quantity comparison of the models used was done by calculating statistical indices such as maximum error $(M E)$, normalized root mean square error ( $n R M S E)$, modelling efficiency $(E F)$, and coefficient of residual mass (CRM). Their mathematical expressions are given below:

$$
\begin{gathered}
M E=\max \left|P_{i}-O_{i}\right|_{i=1}^{n} \frac{100}{\bar{O}}, \\
n R M S E=\left[\frac{\sum_{i=1}^{n}\left(P_{i}-O_{i}\right)^{2}}{n}\right]^{\frac{1}{2}} \frac{100}{\bar{O}}, \\
E F=\frac{\sum_{i=1}^{n}\left(O_{i}-\bar{O}\right)^{2}-\sum_{i=1}^{n}\left(P_{i}-O_{i}\right)^{2}}{\sum_{i=1}^{n}\left(O_{i}-\bar{O}\right)^{2}}, \\
C R M=\frac{\sum_{i=1}^{n} O_{i}-\sum_{i=1}^{n} P_{i}}{\sum_{i=1}^{n} O_{i}},
\end{gathered}
$$

in which $P_{i}$ is the predicted values, $O_{i}$ is measured values, $\mathrm{n}$ is the number of observations and $\bar{O}$ is the average of $O_{i}$.

The performance of the model estimation is better as the $n R M S E$ gets closer to zero. The higher $M E$ values indicate poor estimation by the model. $E F$ varies between $-\infty$ and +1 . EF values closer to one show higher efficiency of the model, whereas $C R M$ indicates the tendency of the model for overestimation or underestimation, compared with the measured values. If all the simulated and measured data are the same, ME, CRM, and $n R M S E$ are zero and $E F$ is one (Loague and Green, 1991).

The parameters of the models were determined by the minimum error square summation optimization method. The differences in the results between the mathematical models based on irrigation water salinity and saturated soil extract salinity were analysed statistically using the T-test for comparison of means. The statistical software IBM SPSS statistics version 23 and MS Excel version 2010 were used in this study.

\section{RESULTS AND DISCUSSION}

Basil response to different salinity levels is given in Fig. 1. As can be seen, up to $1.7 \mathrm{dS} \mathrm{m}^{-1}$, the relative yield is constant and from that point as the salinity of irrigation water increases, the relative yield starts decreasing. Therefore, the basil threshold value to salinity was estimated at $1.7 \mathrm{dS} \mathrm{m}^{-1}$. By fitting the equation of Maas and Hoffman to our measured data, the gradient of basil yield versus salinity was calculated as $10 \%$ per $\mathrm{dS} \mathrm{m}^{-1}$. Based on this, basil is classified as a salinity-sensitive crop.

In order to compare the models, their parameters were determined first by using the minimum error square summation optimization method and fitting the different models on the measured data. These parameters are given in Table 4. Accordingly, the basil threshold value to irrigation water salinity is $1.7 \mathrm{dS} \mathrm{m}^{-1}$ and the yield reduction gradient is $10 \%$ per dS m${ }^{-1}$. In van Genuchten and Hoffman (1984) (Eq. (3)) and Dirksen and Augustijn (1988) (Eq. (4)), the salinity at which yield decreases by $50 \%\left(E C_{50}\right)$ is $6 \mathrm{dS} \mathrm{m}^{-1}$. The amounts of $\mathrm{p}$ of van Genuchten and Hoffman (1984) and Homaee et al. (2002a) (Eq. (6)) are 2.1 and 1.31, respectively. The $\alpha_{0}$ coefficient in the model of Homaee $e t$ al. (2002a) is 0.24 .

The fit of the simulated math-empirical and statistical models based on irrigation water salinity and measured data is given in Figs 2 and 3. Evaluated statistical indices of the models are given in Table 5. The results indicate that the

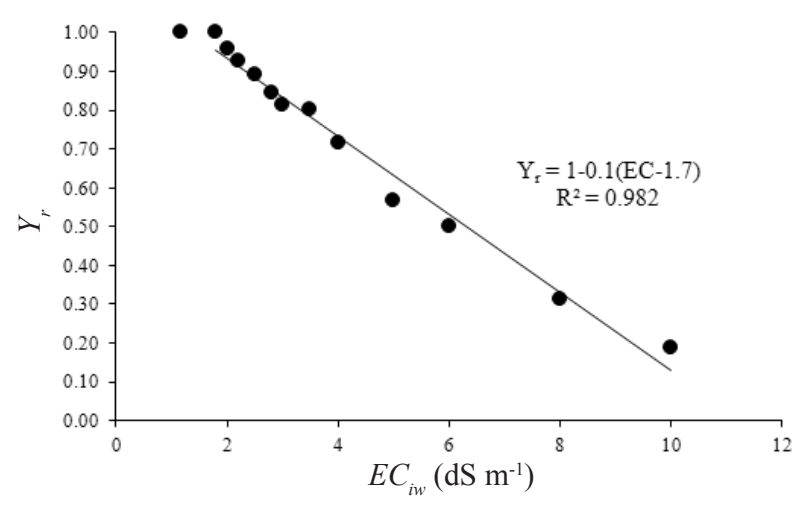

Fig. 1. Basil response to irrigation water salinity stress. 


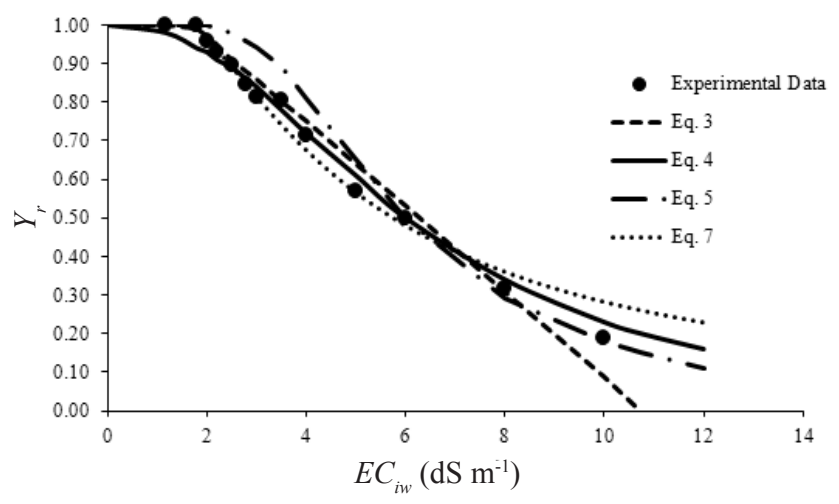

Fig. 2. Mathematical-empirical functions based on electrical conductivity of the irrigation water.

modified discount model for simulation of the basil reduction function based on irrigation water salinity conforms better to the measured data than the other models (the least $n R M S E$ and $M E$ ). Considering the presented results, it seems that among math-empirical models for salinity stress conditions, the model of van Genuchten and Hoffman (1984) is more accurate than the Maas and Hoffman (1977), Dirksen and Augustijn (1988) and Homaee et al. (2002a) models. The papers of Green et al. (2006) and Skaggs et al. (2006) present the same conclusion. Our results have indicated that all the statistical models yield figures very close to one another and their results are all acceptable. Our work has indicated that statistical models have higher precision than math-empirical models. Steppuhn et al. (2005a) reported that statistical models had higher accuracy than the mathempirical model of Maas and Hoffman (1977) and among statistical models the modified discount model had the best fit on measured data, which is in good agreement with the results of this study.

The T-test for comparison of means is used for comparison of two groups of statistical and mathematical models with each other and also with the measured data (Table 5). The results indicate that there are no significant differences between the statistical models and the measured data and the two model groups at a 5\% probability level. The cause of this may be the adopted adequate leaching requirement and the short root zone of basil.

As mentioned before, saturated soil extracted salinity changes during the growing season and the measurements are both costly and time consuming. The measurements of irrigation water salinity are easy and cheap. Considering the shallow roots of basil, it is assumed that adoption of an adequate leaching requirement can replace saturated soil extract salinity with irrigation water salinity in these models. This has an effective role in practical application of plant response models in farm water management because estimating the plant response based on a constant parameter can provide a better and more practical water management practice. Statistical indices for accuracy test of the mathematical model results under two conditions of irrigation
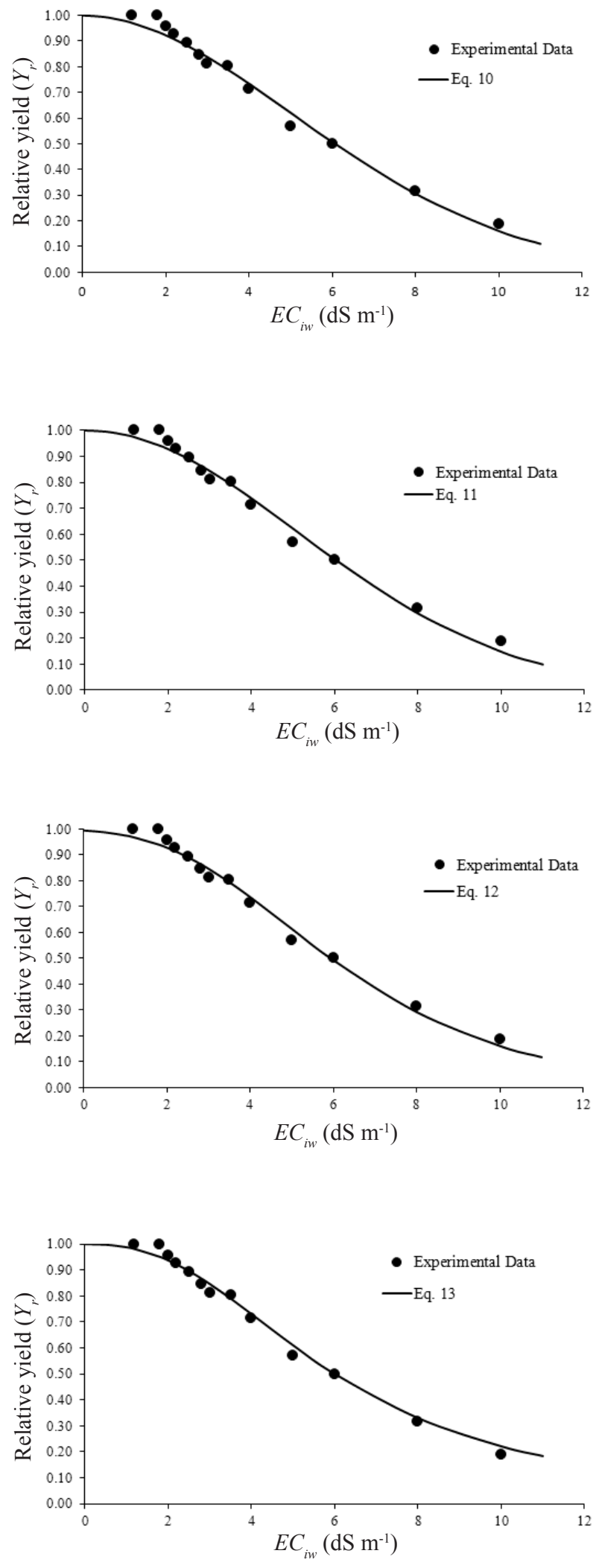

Fig. 3. Statistical functions based on electrical conductivity of the irrigation water. 
T a b l e 4. Calculation of parameters of studied models

\begin{tabular}{|c|c|c|c|c|c|c|c|c|c|}
\hline \multirow{2}{*}{ Eq. No. } & $E C^{*}$ & $E C_{\text {max }}$ & $E C_{50}$ & \multirow{2}{*}{$b(\%)$} & \multirow{2}{*}{$C$} & \multirow{2}{*}{$a$} & \multirow{2}{*}{$s(\%)$} & \multirow{2}{*}{$p$} & \multirow{2}{*}{$\alpha_{0}$} \\
\hline & & $\left(\mathrm{dS} \mathrm{m} \mathrm{m}^{-1}\right.$ & & & & & & & \\
\hline 2 & 1.70 & - & - & 10 & - & - & - & - & - \\
\hline 3 & - & - & 6.00 & - & - & - & & 2.10 & - \\
\hline 4 & 1.70 & - & 6.00 & - & - & - & & 2.10 & - \\
\hline 6 & 1.70 & 10.75 & - & - & - & - & & 1.31 & 0.24 \\
\hline 9 & - & - & - & - & -0.021 & 1.94 & & - & - \\
\hline 10 & - & - & - & - & 0.00097 & 0.019 & & - & - \\
\hline 11 & - & - & - & - & -5.156 & -0.338 & & - & - \\
\hline 12 & - & - & 6.00 & - & - & - & 0.15 & - & - \\
\hline
\end{tabular}

*EC is the maximum value of salinity without a basil yield reduction.

T a b l e 5. Calculated statistical indices for comparison of different models in estimating basil yield reduction functions based on irrigation water salinity

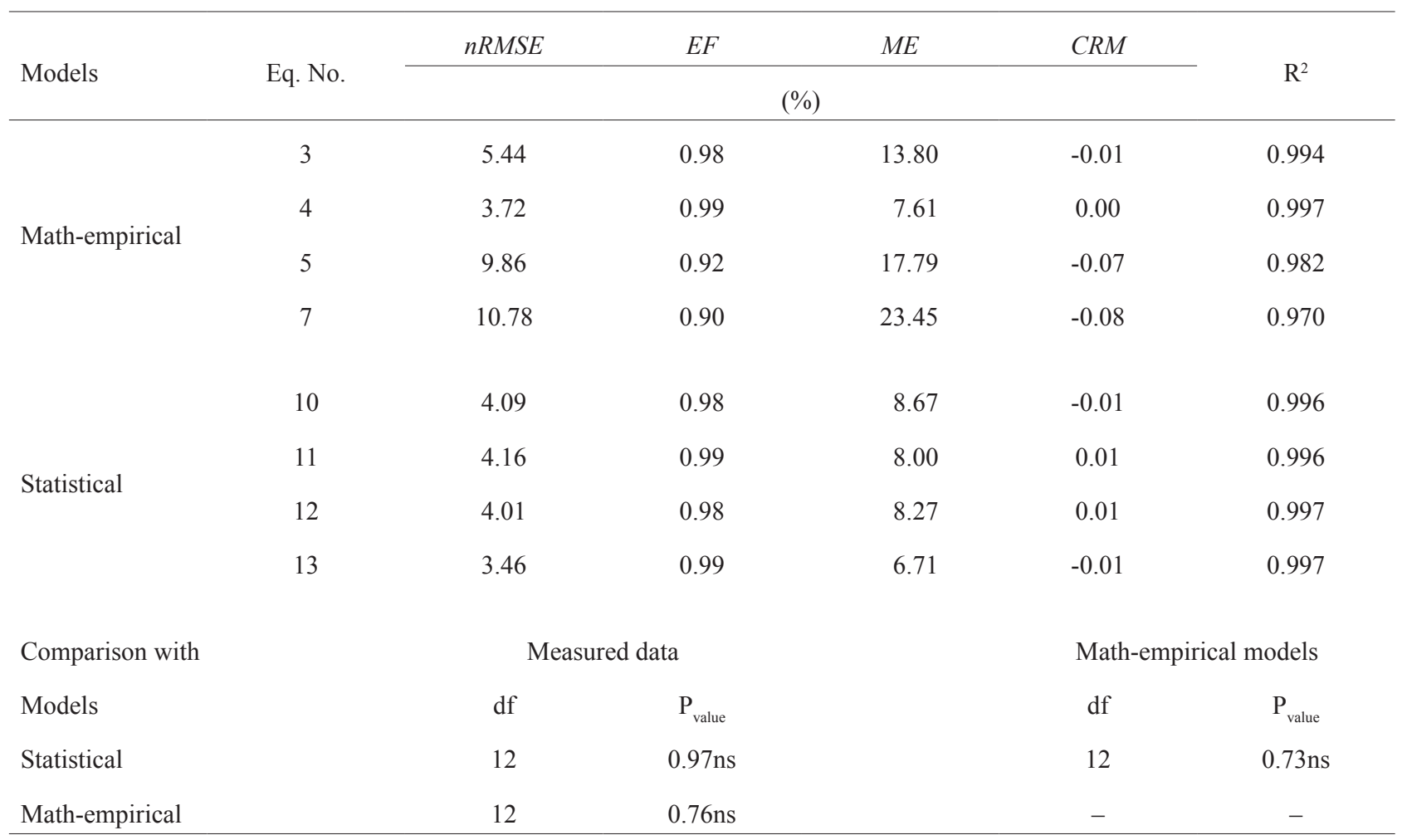

water salinity and saturated soil extract salinity are given indicated that in all models there are no significant diffein Table 6. The results have indicated that in most cases, modelling basil response based on irrigation water salinity has a higher precision than modelling based on saturated soil extract salinity (Table 7).

The Student T-test for comparison of means is used to compare the statistical indices of two modelling methods (math-empirical and statistical models). The results have rences at a $5 \%$ level. Consequently, the use of irrigation water salinity can be substituted for saturated soil extract salinity directly. The use of irrigation water salinity instead of saturated soil extract salinity can help the practical application of the models for vegetables with shallow roots in farm water salinity management. The plant response to different salinity levels in using brackish water to achieve 
T a b l e 6. Calculated statistical indices for comparison of different models for estimating basil reduction functions based on both irrigation water salinity and saturated soil extract salinity

\begin{tabular}{|c|c|c|c|c|c|c|c|c|}
\hline \multirow{2}{*}{$\begin{array}{c}\begin{array}{c}\text { Comparison } \\
\text { with }\end{array} \\
\text { Eq. No. }\end{array}$} & \multicolumn{4}{|c|}{ Irrigation water salinity } & \multicolumn{4}{|c|}{ Saturated soil extract salinity } \\
\hline & $n R M S E$ & $M E$ & $C R M$ & \multirow[t]{2}{*}{$\mathrm{R}^{2}$} & $n R M S E$ & $M E$ & $C R M$ & \multirow[t]{2}{*}{$\mathrm{R}^{2}$} \\
\hline \multicolumn{4}{|c|}{$(\%)$} & & \multicolumn{3}{|c|}{$(\%)$} & \\
\hline 2 & 5.44 & 13.80 & -0.01 & 0.994 & 6.80 & 16.80 & -0.02 & 0.991 \\
\hline 3 & 3.72 & 7.61 & 0.00 & 0.997 & 4.04 & 8.66 & 0.01 & 0.996 \\
\hline 4 & 9.86 & 17.79 & -0.07 & 0.982 & 10.75 & 19.32 & -0.07 & 0.978 \\
\hline 6 & 10.78 & 23.45 & -0.08 & 0.970 & 5.84 & 15.99 & -0.04 & 0.992 \\
\hline 9 & 4.09 & 8.67 & -0.01 & 0.996 & 4.45 & 8.98 & 0.003 & 0.995 \\
\hline 10 & 4.16 & 8.00 & 0.01 & 0.996 & 4.29 & 8.25 & 0.01 & 0.996 \\
\hline 11 & 4.01 & 8.27 & 0.01 & 0.997 & 4.13 & 8.47 & 0.01 & 0.996 \\
\hline 12 & 3.46 & 6.71 & -0.01 & 0.997 & 3.65 & 7.04 & -0.01 & 0.997 \\
\hline
\end{tabular}

T a b l e 7. T-test analyses of comparison between irrigation water salinity and saturated soil extract salinity

\begin{tabular}{|c|c|c|c|c|c|c|}
\hline \multirow{2}{*}{ Eq. No. } & \multicolumn{2}{|c|}{ Irrigation water salinity } & \multicolumn{2}{|c|}{ Saturated soil extract salinity } & \multirow{2}{*}{$\mathrm{df}$} & \multirow{2}{*}{$\mathrm{P}_{\text {value }}$} \\
\hline & Mean & Variance & Mean & Variance & & \\
\hline 2 & 0.74 & 0.08 & 0.75 & 0.08 & 12 & $0.95 \mathrm{~ns}$ \\
\hline 3 & 0.73 & 0.06 & 0.73 & 0.06 & 12 & $0.96 \mathrm{~ns}$ \\
\hline 4 & 0.78 & 0.08 & 0.79 & 0.09 & 12 & $0.98 \mathrm{~ns}$ \\
\hline 6 & 0.80 & 0.05 & 0.75 & 0.06 & 12 & $0.59 \mathrm{~ns}$ \\
\hline 9 & 0.73 & 0.07 & 0.73 & 0.06 & 12 & $0.97 \mathrm{~ns}$ \\
\hline 10 & 0.73 & 0.07 & 0.72 & 0.07 & 12 & $0.99 \mathrm{~ns}$ \\
\hline 11 & 0.73 & 0.07 & 0.73 & 0.07 & 12 & $0.99 \mathrm{~ns}$ \\
\hline 12 & 0.73 & 0.06 & 0.74 & 0.06 & 12 & $0.98 \mathrm{~ns}$ \\
\hline
\end{tabular}

economical crop yield is very important. On the other hand, with the adoption of adequate leaching requirements, irrigation water salinity, which is a constant parameter can easily be measured with little cost instead of saturated soil extract salinity, is very useful for practical application of these models to on-farm water quality management. It is believed that the plant response based on a constant parameter may change farm water management from research levels to a more practical level.

\section{CONCLUSIONS}

1. The results of this study indicated that the basil threshold value obtained based on irrigation water salinity was $1.7 \mathrm{dS} \mathrm{m}^{-1}$ and the gradient of yield reduction was $10 \%$ per $\mathrm{dS} \mathrm{m}^{-1}$.
2. The general conclusion reached was that among the math-empirical reduction functions. The model with the lowest normalized root mean square error $3.72 \%$ and maximum error $7.61 \%$ had the highest accuracy among all models.

3. The results also indicated that although all statistical models gave acceptable simulations, the modified discount model presented the most acceptable simulation. Considering the basil shallow root length and the fact that surface irrigation systems used mostly for irrigation of vegetables such as basil, spinach, cress, leek, and savoury usually have a high amount of deep percolation as a result of high leaching requirements, irrigation water salinity can be used directly in these models replacing the saturated soil extract salinity. 
Conflict of interest: The Authors do not declare conflict of interest.

\section{REFERENCES}

Ayars J.E., Corwin D.L., and Hoffman G.J., 2012. Leaching and root zone salinity control. ASCE Manual and Report Engineering Practice No. 71 Agricultural Salinity Assessment and Management, ASCE Riston, Chapter, 12: 371-403.

Baker C.H., Horrocks R.D., and Goering C.E., 1975. Use of the Gompertz function for predicting corn leaf area. Trans. ASAE, 18(2), 332-336.

Chartzoulakis K. and Klapaki J., 2000. Response of two greenhouse pepper hybrids to $\mathrm{NaCl}$ salinity during different growth stages. SciHortic., 86, 247-260.

De Wit C.T., 1958. Transpiration and Crop Yields. Versl. Landbouwk. Onderz., Pudoc, Wageningen, Netherland.

Dirksen C. and Augustijn D.C., 1988. Root water uptake function for non-uniform pressure and osmotic potentials. Agric. Abstracts, 1-188.

Dirksen C., Kool J.B., Koorevaar P., Van Genuchten M.Th., 1993. HYSWASOR-simulation model of hysteretic water and solute transport in the root zone. In: Water Flow and Solute Transport in Soils (Eds D. Russo, G. Dagan). Springer, New York, USA.

Dudley L.M. and Shani U., 2003. Modeling plant response to drought and salt stress: reformulation of the root-sink term. Vadose Zone J., 2, 751-758.

Ekren S., Sonmez C., Ozcakal E., KukulKurttas Y.S., Bayram E., and Gurgulu H., 2012. The effect of different irrigation water levels on yield and quality characteristics of purple basil (Ocimumbasilicum L.). Agric. Water Manag., 57(2), $111-126$

Feddes R.A., Kowalik P., and Zarandy H., 1978. Simulation of field water use and crop yield.Pudoc.Wageningen.The Netherlands saline water in supplemental irrigation of wheat and barley under rainfed agriculture. Agric. Water Manag., 78, 122-127.

Francois L.E., 1996. Salinity effects on four sunflower hybrids. Agron. J., 88, 215-219.

Gan Y., Stobbe E.H., and Moes J., 1992. Relative date of wheat seedling emergence and its impact on grain yield. Crop Sci., $32,1275-1281$.

Gompertz B., 1825. On the nature of the function expressive of the law of human mortality and on a new mode of determining the value of life contingencies. R. Soc. London Phil. Trans., 36, 513-585.

Green S.R., Kirkham M.B., and Clothier E., 2006. Root uptake and transpiration: From measurements and models to sustainable irrigation. Agric. Water Manag., 86, 165-176.

Homaee M., 1999. Root water uptake under non-uniform transient salinity and water stress. Ph.D. Thesis, Wageningen Agricultural University, The Netherlands.

Homaee M., Dirksen C., and Feddes R.A., 2002a. Simulation of root water uptake. I. Non-uniform transient salinity using different macroscopic reduction functions. Agric. Water Manag., 57, 89-109.

Homaee M., Feddes R.A., and Dirksen C., 2002c. Simulation of root water uptake. III. Non-uniform transient combined salinity and water stress. Agric. Water Manag., 57, 127-144.
Hosaini Y., Homaee M., Karimian N.A., and Saadat S., 2009. Modeling vegetative stage response of canola (Brassica napus L.) to combined salinity and boron tresses. Int. J. Plant Prod., 3(1), 91-104.

Lapp M.S., Skoropad W.P., 1976. A mathematical model of conidial germination and appressorial formation for Colletotrichum graminiocola. Can. J. Bot., 54(19), 2239-2242.

Loague K. and Green R.E., 1991. Statistical and graphical methods for evaluating solute transport models: overview and application. J. Contam. Hydrol., 7, 51-73.

Maas E.V., Hoffman G.J., 1977. Crop salt tolerance-current assessment. J. Irrig. Drain Div., ASCE, 103 (IR2), 115-134.

Marotti M., Piccaglia P., and Giovanelli E., 1996. Differences in essential oil composition of basil (Ocimumbasilicum J.) Italian cultivars related to morphological characteristics. J. Agric. Food Chem., 44, 3926-3929.

Miller J.D. and Gaskin G., 1997. The development and application of the theta probes soil water sensor. MLURI. Technical Note, 1-312.

Shenker M., Ben-Gal A., and Shani U., 2003. Sweet corn response to combined nitrogen and salinity environmental stresses. Plant Soil, 256, 139-147.

Skaggs T.H., van Genuchten M.Th., Shouse P.J., and Poss J.A., 2006. Root uptake and transpiration: From measurements and models to sustainable irrigations. Agric. Water Manag., 86, 140-179.

Steppuhn H., Wall K., Rasiah V., and Jame Y.W., 1996. Response functions for grain yield from spring-sown wheats grown in saline rooting media. Can. Agric. Eng., 38(4): 249-256.

Steppuhn H., Wang H., and Gan Y., 1998. Evaluating Russian wild ryegrass emergence from saline seedbeds using the Gompertz function. Can. Agric. Eng., 40(4): 241-247.

Steppuhn H., van Genuchten M.Th., and Grieve C.M., 2005a. Crop ecology, management and quality: Root-Zone Salinity: I. Selecting a Product-Yield Index and Response Function for Crop Tolerance. Crop Sci., 45(1), 209-220.

Steppuhn H., van Genuchten M.Th., and Grieve C.M., 2005 b. Crop ecology, management and quality: Root-Zone Salinity: II. Indices for Tolerance in Agricultural Crops. Crop Sci., 45(1), 221-232.

Taylor G.J., Stadt K.J., and Dale M.R.T., 1991. Modeling the phyto-toxicity of aluminum, cadmium, copper, manganese, nickel, and zinc using the Weibull frequency distribution. Can. J. Bot., 69(2), 359-367.

van Genuchten M.Th. and Gupta S.K., 1993. A reassessment of the crop tolerance response function. J. Indian Soc. Soil Sci., 41(4), 730-737.

van Genuchten M.Th. and Hoffman G.J., 1984. Analysis of crop production. In: Soil salinity under irrigation (Eds I. Shainberg, J. Shalhevet). Springer-Verlag.

Wang D., Poss J.A., Donovan T.J., Shannon M.C., and Lesch S.M., 2002. Biophysical properties and biomass production of elephant grass under saline conditions. J. Arid Environ., 52(4), 447-456.

Weibull W., 1951. A statistical distribution function of wide application. J. Appl. Mech., 18, 293-297. 